\title{
APRENDIZAGEM DE PROFESSES DE LÍNGUA INGLESA: UM ESTUDO EM CONTEXTO DE ENSINO COLABORATIVO
}

\section{ENGLISH AS A FOREING LANGUAGE TEACHERS' LEARNING: A STUDY IN A COLLABORATIVE TEACHING CONTEXT}

\author{
Ágatha Demarque de Lacqua ${ }^{23}$
}

\begin{abstract}
RESUMO: Esse artigo tem como objetivo discutir de que maneira a aprendizagem de professores de língua inglesa, em formação inicial e contínua, se desvela em textos produzidos por eles durante o processo de ensino colaborativo. Os contextos da pesquisa foram salas de aula, tanto no espaço da formação de professores na Universidade Estadual de Londrina (UEL), quanto em espaços de $9^{\circ}$ ano do Ensino Fundamental de uma escola pública em Londrina-Pr. As raízes teóricas desse artigo estão nas práticas colaborativas de ensino, conhecidas como Ensino colaborativo ou Coteaching (ROTH, TOBIN, ZIMMERMANN, 2002). O estudo envolve sete participantes no geral: uma professora formadora do curso de Letras Inglês e do Programa de Pós graduação em Estudos da Linguagem (UEL); quatro licenciandos de Letras Inglês; o professor regente da rede pública de educação básica; e a professora pesquisadora. A coleta de dados foi realizada em 2017 e os instrumentos utilizados foram gravações em áudio de reuniões que tinham como objetivo planejar e refletir sobre o ensino colaborativo de língua inglesa. Para análise de dados, utiliza-se a abordagem Análise do Discurso Crítica (FAIRCLOUGH, 2009) e as categorias de Modalidade e Avaliação sugeridas por Fairclough (2003a) para análise linguística em ADC (FAIRCLOUGH, 2003a; RAMALHO, RESENDE, 2011). O estudo também inserese na área de Linguística Aplicada, no campo de Formação de professores e tem como unidade de análise práticas discursivas. Neste artigo, discuto como o processo de aprendizagem de professores de desvela, tanto em posicionamentos, representações e identificações analisadas em textos produzidos pelos participantes; quanto em como os discursos são articulados, reproduzidos e transformados durante o processo de ensino colaborativo.
\end{abstract}

PALAVRAS-CHAVE: Linguística Aplicada. Formação de professores. Ensino Colaborativo/ Coteaching. Aprendizagem de professores.

ABSTRACT: This research aims to discuss how English teachers's learning, either being in initial or continuing training, is revealed in texts produced by them during the Coteaching process. The contexts of the research are classrooms, either in rooms destined to teacher training at UEL, or in Elementary School 9th grade rooms at a public school in Londrina-Pr. The theoretical bases of this article are embedded in collaborative teaching practices, known as Collaborative Teaching or Coteaching (ROTH, TOBIN, ZIMMERMANN, 20 02). The study involves seven participants in general: a professor who teachers in both Letras Inglês course (an English language teaching course) and Language Studies postgraduate course (both at UEL); four undergraduate students; the regent teacher of the public basic education network; and the researcher teacher. The data were collected in 2017 and the instruments used were audio recordings of weekly meetings, which aimed to plan and reflect about Coteaching English as a foreign language. The data analysis was based upon the Critical Discourse Analysis approach (FAIRCLOUGH, 2009), as well as upon the categories of modality and evaluation, suggested by Fairclough (2003a) to be used in CDA (FAIRCLOUGH, 2003a; RAMALHO, RESENDE, 2011). This article is part of studies in the area of Applied Linguistics, in the field of Teacher training and it has discursive practices as analysis units. In this article, it is discussed how the process of teacher learning is revealed, either in positioning, representations and identifications analyzed in texts produced by the participants, or in how discourses are articulated, reproduced and transformed during the process of Coteaching.

KEYWORDS: Applied Linguistics. Teacher training. Collaborative Teaching/Coteaching. Teacher's Learning.

\section{Introdução}

Dentre as teorias de aprendizagem que pavimentaram o caminho do processo de formação de professores, encontra-se a perspectiva sócio-histórico-cultural de Leontiev e

\footnotetext{
${ }^{23}$ Mestranda no Programa de Pós-Graduação em Estudos da Linguagem da Universidade Estadual de Londrina. Bolsista Capes. Orientada pela Profa. Dra. Elaine Fernandes Mateus (UEL). E-mail: agathalacqua@gmail.com
} 
Vygotsky, que ganhou muita atenção no Brasil a partir dos anos oitenta (LIBÂNEO, 2004) e abrange estudos em diferentes áreas, como antropologia, psicologia, educação e linguística aplicada. A perspectiva sócio-histórico-cultural estuda a construção do aprendizado ou desenvolvimento cognitivo humano e, de acordo com estudiosos que se baseiam nela, entende-se que a aprendizagem se dá por meio de práticas sociais (EDWARDS, 2010; GUTIERREZ, 2000; JOHNSON, 2009; LEWIS, PYSCHER, STUTELBERG, 2014; LIBÂNEO, 2004; MAZZEU, 2009). Essa perspectiva busca explicar o desenvolvimento humano mental, considerando, em sua análise, as situações culturais, institucionais e históricas das práticas sociais em que ele ocorre (JOHNSON, 2009).

Para os estudiosos que seguem a linha de pensamento de Vygotsky, a aprendizagem é resultado de influências externas, como relações sociais, e internas, como funções psíquicas, sendo as relações sociais primárias e essenciais para transformações de funções psíquicas (PONTECORVO, AJELLO \& ZUCCHERMAGLIO, 2005). Mateus (2014) define o conceito de aprendizagem como "[...]ocupação subjetiva de posições previamente dadas em práticas sociais, [...] nas/das quais a ação discursiva é um dos elementos essenciais." (MATEUS, 2014, p. 337). Ao assumir determinados posicionamentos, os atores da ação social podem tanto reproduzir tudo aquilo que já vem sido feito e dito, processo denominado "reprodução social", quanto podem deixar de reproduzir para transformar o ambiente em que está inserido, gerando "mudança social" (MATEUS, 2014). O potencial transformador permite aos atores sociais, transitar entre os processos de "reprodução" e "mudança" social em textos produzidos por eles, bem como nos posicionamentos, identificações e representações revelados em textos. O processo de aprendizagem, por sua vez, relaciona-se tanto com a reprodução e mudança social, quanto à apropriar-se de e reconstruir discursos (LEWIS, KETTER, 2004).

Considerando a aprendizagem de professores, busquei examinar como os professores se posicionaram durante o processo de ensino colaborativo, construindo, reconstruindo, articulando e até mesmo apropriando-se de discursos, ora conflitantes, ora similares. É essa articulação de identificações e representações que caracteriza, de maneira geral, o processo de aprendizagem professores em formação neste artigo. Quando me refiro à identificação e representação, faço-o com base nas definições de discurso de Fairclough (2003).

Nas vozes de Ramalho e Resende (2011), “[...] O discurso tem três principais significados nas práticas: ação e interação, representação de aspectos do mundo e (auto) identificação. Esses três significados são simultâneos em toda prática: a linguagem é funcionalmente complexa. (RAMALHO, RESENDE, 2011, p.43). Os três significados do discurso podem ser analisados separadamente no que se diz respeito à análise linguística, entretanto, os três sentidos estão interligados no discurso (em seu sentido abstrato). Tratando especificamente de representações e identificações, "[...] Discursos são maneiras relativamente estáveis de representar aspectos do mundo, de pontos de vista particulares. Estilos, por fim, são maneiras relativamente estáveis de identificar, discursivamente, a si e a outrem. (RAMALHO, RESENDE, 2011, p.44). Assim sendo, representações são "[...] tipos de linguagem usados para construir algum aspecto da realidade de uma perspectiva particular", enquanto estilos são "[...] tipos de linguagem usados por uma categoria particular de pessoas e relacionados com sua identidade" (RAMALHO, RESENDE, 2011, p.47).

O processo de aprendizagem de professores em formação inicial e contínua para esse artigo se deu em práticas sociais de Ensino Colaborativo, ou Coteaching (ROTH, TOBIN, ZIMMERMANN, 2002), que abriu espaços aos professores participantes para planejar, refletir e discutir sobre a prática docente. No processo de Ensino colaborativo, o pesquisador, investigador da teoria e da prática, vivencia na prática seu objeto de pesquisa, libertando-se do papel fixo de observador para participar ativamente de práticas sociais relativas a pesquisa (BRAY, 2000). Assim sendo, mesmo tendo interesse no aspecto investigativo do processo de 
pesquisa como pesquisadora do PPGEL, constituí-me como participante ativa em sala de aula, vivenciando meu objeto de pesquisa em prática com os outros professores. Afinal, em Ensino Colaborativo, a proposta é que tanto alunos e professores, quanto pesquisadores e supervisores tenham seus papéis fixos descontruídos para que possam participar em sala de aula e tenham chances de se posicionar, bem como estreitar os laços entre teoria e observação, suprindo duas lacunas educacionais como entre as teorias de educação e práticas de ensino e entre práticas de pesquisa e práticas de ensino (BRAY, 2000; ROTH, TOBIN, ZIMMERMANN, 2002). O Coteaching é, portanto, uma proposta que permite a realização de pesquisa participante, na qual todos os sujeitos, ao interagirem em sala de aula, têm o potencial de transformar não só a si mesmos, mas também o contexto em que estão envolvidos.

O objetivo deste artigo é analisar de que maneiras a aprendizagem de professores em formação inicial e contínua se desvela em textos produzidos por eles durante o processo de ensino colaborativo de língua inglesa. Dentre os objetivos específicos de minha pesquisa, busco: a) investigar relações entre os educadores em sua rotina escolar; e b) identificar posicionamentos, identificações e representações que caracterizem o processo de aprendizagem em práticas discursivas durante o processo de ensino colaborativo. Para alcançar os objetivos, as perguntas que guiaram esse estudo são: a) que posicionamentos os professores assumem durante discussões em reuniões?; b) que identificações e representações se fazem presentes nos posicionamentos de professores?; e c) o que os posicionamentos revelam sobre o processo de aprendizagem dos professores durante o processo de ensino colaborativo?.

Este artigo tem bases teóricas e metodológicas na perspectiva de análise do discurso crítica (ADC) de Fairclough (1985), que possibilita conceituar discurso, linguagem e prática social. A ADC considera o discurso, em todos os seus contextos, como um fenômeno prático, social e cultural, que pode ser materializado em textos. Em meio a estudiosos da ADC, há os que buscam explicar como as ideologias e relações de poder que estruturam a sociedade se fazem presentes no discurso e como esse pode promover perpetuação de antigos ou construção de novos sentidos (COTS, 2006; JASNIVSKI, SILVA, 2011; MATEUS, 2014; MATEUS, RESENDE, 2014).

Fairclough (2009) trata a ideia de discurso, em sua forma geral e mais superficial, como semiose, representando uma visão mais abstrata de discurso (FAIRCLOUGH, 2009). Ramalho e Resende definem discurso como "maneiras relativamente estáveis de representar, de (inter)agir e de identificar(-se) em práticas sociais materializadas em textos" (RAMALHO, RESENDE, 2011, p. 112). Considerando a materialização do discurso em texto, refiro-me à análise de discursos como análise de textos e, segundo Ramalho e Resende (2011), são temas relevantes para a pesquisa em ADC: "[...] a representação de aspectos específicos do mundo por meio de discursos particulares; e os modos como grupos específicos de atores sociais atualizam discursos particulares na representação de sua experiência, etc.” (RAMALHO, RESENDE, 2011, p. 58). Este artigo insere-se, portanto, nos temas relevantes sugeridos pelas autoras, já que analisou o processo de aprendizagem de professores, discutindo representações e identificações em textos produzidos por eles em práticas sociais, mais especificamente, durante o processo de ensino colaborativo.

Ao relacionarmos identificações e representações à ideia de discurso ou semiose, parto do pressuposto de que "O discurso é o meio pelo qual os participantes constroem sua realidade, a si próprios e aos outros a sua volta, em um movimento fluido e constante" (CAMPOS, 2013, p.38). Dentro dos pressupostos teóricos da Análise Crítica do Discurso, Fairclough (2003a), baseado em Halliday, propõe algumas categorias de análises, exploradas por estudiosos da teoria e que podem ser aplicadas a análise de textos (FAIRCLOUGH, 2003a; RAMALHO, RESENDE, 2011). 
As categorias de análise, ou categorias analíticas, são "formas e significados textuais associados a maneiras particulares de representar, de (inter)agir e de identificar(-se) em práticas sociais situadas" (RAMALHO, RESENDE, 2011, p. 112) que nos permitem estabelecer conexões entre textos e os efeitos sociais que eles podem ter. Dentre as categorias analíticas, estão: aspectos discursivos/textuais; estrutura genérica; intertextualidade; presunção; relações semânticas/gramaticais entre períodos e orações; trocas, função da fala, modo gramatical; interdiscursividade; representações de eventos/fatores sociais; identificação; modalidade; e avaliação (RAMALHO, RESENDE, 2011). Para este artigo, utilizei as categorias de modalidade e avaliação, sugeridas por Fairclough (2003a) como adequadas para a análise de processos de identificação.

Segundo o autor, as categorias de modalidade e avaliação estão relacionadas a como os atores sociais demonstram-se comprometidos no texto, explicitando o que é verdadeiro e necessário (modalidade) e o que é bom ou ruim, desejável ou não (avaliação), sendo esse comprometimento parte de como eles se identificam e identificam outras pessoas, bem como representam visões de mundo. (FAIRCLOUGH, 2003a). A categoria de modalidade está relacionada com como os atores se comprometem ao fazer "[...]afirmações, perguntas, exigências e ofertas" (FAIRCLOUGH, 2003a, p.165) e o comprometimento pode ser observado pela escolas lexicais tomadas ao produzir o texto, como os verbos utilizados. Ramalho e Resende destacam algumas questões propostas por Fairclough que podem ser aplicadas a análise do texto ao analisar modalidade:

Como os autores se comprometem em termos de verdade (modalidades epistêmicas)? Em termos de obrigação e necessidade (modalidades deônticas)? Em que extensão as modalidades são categóricas (afirmação, negação etc.)? Em que extensão são modalizadas (com marcadores explícitos de modalidade)? Que níveis de comprometimento observam-se (alto, médio, baixo) quando há marcadores explícitos de modalidade? Quais são os marcadores de modalização (verbos modais, advérbios modais etc.) (RAMALHO, RESENDE, 2011, p. 116)

A categoria de modalidade nos permite observar como o falante se compromete em sua fala com o mundo ao seu redor, podendo estabelecer uma relação entre o falante e representações contidas em suas falas (FAIRCLOUGH, 2003a). Dentro dessa categoria, existem tipos de trocas, funções de discurso e tipos de modalidades. Fairclough (2003a) apresenta dois tipos de troca, a troca de conhecimentos e a de atividades. A troca de conhecimentos, ou 'modalidade epistêmica', pode ser apresentada por funções do discurso como declarações que, por sua vez, podem aparecer como asserções, modalizações e negações, estando o texto modalizado em um meio termo entre uma afirmação e uma negação, representando um comprometimento intermediário em vez de dizer que algo é ou não verdade.

Além de declarações, ainda em modalidade epistêmica, a função do discurso pode aparecer em forma de pergunta, situação na qual o ator social cede ao outro o comprometimento com a verdade. As perguntas podem ser feitas de maneiras nãomodalizadas positivas, modalizadas ou não-modalizadas negativas, sendo que a modalização sempre indica um nível intermediário de comprometimento. Já o segundo tipo de troca apresentado por Fairclough (2003a), a troca de atividades, ou 'modalidade deôntica', pode aparecer em funções do discurso em forma de exigências/demandas ou ofertas. As exigências revelam o comprometimento com obrigações/necessidades e podem ser apresentada como prescrições, modalizações e proscrições, sendo as prescrições, geralmente, orações imperativas e afirmativas; as modalizações caracterizadas por verbos modais; e as proscrições como orações imperativas negativas.

Além das exigências ou demandas, a troca de atividades pode ser representada por orações de oferta, que revelam o comprometimento do falante com a ação, seja quando o ator 
social resolve trazer a responsabilidade da ação para ele, se propondo a realizar determinada ação; de maneira modalizada; ou recusando-se a fazer algo. De toda maneira, a modalização sempre estará em um nível intermediário de responsabilidade e assunção. Para melhor ilustrar os níveis de comprometimento, Fairclough (2003a) apresenta um quadro, baseado em Halliday (1994):

\begin{tabular}{lll}
\hline & Truth & Obligation \\
\hline High & certainly & required \\
Median & probably & supposed \\
Low & possibly & allowed \\
\hline
\end{tabular}

(Fairclough, 2003a, p. 170)

À esquerda, estão os níveis de comprometimento, do mais alto para o mais baixo; na coluna do meio, estão relacionados os níveis com a modalidade epistêmica, que variam de acordo com os advérbios de modo; e à direita, com a modalidade deôntica, variando de acordo com os adjetivos. Além dos apresentados, alguns outros elementos podem ajudar a evidenciar o comprometimento dos falantes com o que se diz, como o uso dos pronomes pessoais (em primeira ou terceira pessoa, seja do singular ou plural); a entonação utilizada, como, por exemplo, se o falante foi hesitante, assertivo, confiante; entre outros elementos que podem ser levado em consideração para a análise. (FAIRCLOUGH, 2003a).

Além da categoria de 'modalidade' e atrelado à ela, está a de 'avaliação', que nos permite observar como os atores sociais se comprometem em termos de valores ao produzirem textos, demonstrando nesses o que valorizam, desvalorizam, consideram desejáveis, indesejáveis, bom ou ruim. As avaliações podem aparecer em diferentes formas, como: "[...]afirmações avaliativas; afirmações com modalidades deônticas; avaliações afetivas (relacionadas a eventos psicológicos mentais afetivos, como percepções, reflexões e sentimentos); e presunções valorativas (implícita, sem marcadores aparentes) (RAMALHO, RESENDE, 2011,p. 119). No geral, os traços avaliativos podem ser observados nos verbos, adjetivos e advérbios presentes no texto (FAIRCLOUGH, 2003a). Além disso, para fins de análise linguística com base nessas categorias, o analista pode levar em conta as perguntas relacionadas à avaliação propostas por Fairclough (2003a) e adaptadas por Ramalho e Resende, como: "[...]Com que valores (em termos do que é desejável ou indesejável) o/a autor/a se compromete? Como valores são realizados - como afirmações avaliativas, afirmações com modalidades deônticas, afirmações com processos mentais afetivos, valores presumidos?" (RAMALHO, RESENDE, 2011, p. 116).

Nessa seção, busquei explanar os conceitos teóricos que dão base a este artigo, os objetivos e alguns conceitos necessários para compreender a análise linguística de textos. $\mathrm{Na}$ próxima seção, 'Metodologia', apresentei informações sobre o contexto, os participantes, nossos encontros e dados coletados. Em seguida, encontra-se a análise de dados, primeiramente em um nível pontualmente linguístico e micro, que deu suporte para interpretações e discussões de dados em um nível mais amplo, seguido de algumas conclusões de meu trabalho, por meio do qual espero contribuir para os estudos em formação de professores no que diz respeito ao processo de aprendizagem de professores em contextos de colaboração.

\section{Metodologia}

O processo investigativo para esse artigo realizou-se em contextos de sala de aula, tanto no espaço de discussões semanais na UEL quanto em espaços de uma escola pública em 
Londrina-Pr., durante aulas de inglês ministradas em um grupo de nono ano do ensino fundamental. Dados foram coletados em ambos os contextos, entretanto, de modo a investigar o processo de aprendizagem de professores, analisei textos produzidos pelos participantes durante as reuniões na UEL, já que foi o contexto em que discutíamos, nos posicionando sobre o processo de ensino colaborativo.

As reuniões envolviam sete participantes no geral: uma professora formadora do curso de Letras Inglês -UEL e do Programa de Pós graduação em Estudos da Linguagem UEL; quatro licenciandos, dois de um terceiro e dois de um quarto ano do curso de Letras Inglês -UEL e orientandos da professora formadora; o professor regente da rede pública de educação básica; e eu como professora pesquisadora, aluna do curso de Mestrado em Estudos da Linguagem -UEL. O curso de Letras Inglês da UEL tem quatro anos de duração, sendo o terceiro e quarto anos as séries em que os licenciandos devem estagiar, ou seja, ocupar o papel de professor em salas de aula de redes públicas de ensino.

Com relação a obrigatoriedade de comparecer tanto aos encontros quanto às regências, durante a terceira e quarta série do curso de licenciatura Letras Inglês -UEL, os licenciandos devem realizar o estágio em docência e estarem devidamente matriculados nas disciplinas de estágio denominadas 'Estágio Supervisionado', ou 3EST 113, para a terceira série, e 3 EST 114, para a quarta. Estas disciplinas são indispensáveis para que os alunos passem para a próxima série ou se graduem e é de extrema importância para a formação docente, já que, para muitos, ela possibilita o primeiro contato com a sala de aula e com a posição de professor dentro de uma sala de aula da rede pública.

Além disso, a disciplina contempla não só a prática docente de regência, mas também disponibiliza tempo e espaço para que sejam realizadas orientações, que aqui denominei como 'reuniões'. Nos encontrávamos em dois momentos: em reuniões semanais na UEL para discutirmos tudo que fosse necessário com relação ao planejamento de aulas e refletirmos sobre o contexto e a prática de ensino; e durante a regência em uma escola pública. Obrigatoriamente, apenas professores formadores e licenciandos participam das reuniões de estágio supervisionado, sendo a presença do professor regente livre e pouco comum. Como realizamos um trabalho de ensino colaborativo, os encontros contavam com a minha presença enquanto professora pesquisadora e a presença do professor regente da escola pública na qual lecionamos. O principal objetivo da participação de todos foi integrar e dar voz a diferentes atores sociais durante o processo de ensino colaborativo, para que todos pudessem participar, contribuir e enriquecer as discussões com suas experiências, crenças, ideias e pontos de vistas. Como a presença de sete professores em uma única sala de aula seria inviável, os licenciandos foram divididos em duplas para a ministração de aulas na escola pública, contendo um aluno da terceira e um da quarta série em cada.

Nossos encontros, ou reuniões, precediam a regência e também continuaram sendo realizadas após o cumprimento dela. Vinte e quatro encontros presenciais foram realizados no total, durante em média duas horas cada. Desses vinte e quatro encontros, quinze foram gravados por mim durante o processo de coleta de dados. Os instrumentos utilizados para a coleta de dados foram Gravações em áudio. A unidade de análise em foco são as práticas discursivas em que os sete participantes puderam estar presentes, já a análise em si baseia-se em contribuições teóricas da Análise do Discurso Crítica e nas categorias de análise de 'Modalidade' e ‘Avaliação' (FAIRCLOUGH, 2003a; RAMALHO, RESENDE, 2011).

Nesse momento, busco analisar identificações e representações presentes em textos produzidos por professores em uma reunião que ocorreu logo no início do processo de reflexão da prática docente, mais especificamente no dia vinte e um de Julho de 2012, que tinha o objetivo de discutir sobre as observações de aulas que estavam sendo realizadas em uma escola da rede pública, de modo a organizar o processo de elaboração das aulas que seriam dadas durante o período de regência na escola. Escolhi analisar os textos oriundos 
dessa gravação pelo fato dela conter vozes dos professores participantes logo no início do trabalho colaborativo e após a observação do contexto em que trabalharíamos. Discutimos sobre nossas percepções do contexto num todo, revelando (auto)identificações e percepções da escola em geral, dos alunos, problemas encontrados, e possíveis soluções que poderíamos tomar na prática de ensino modo a contribuir para a melhoria de condições em que ensinaríamos e aprenderíamos. Trarei, na seção seguinte, 'discussão dos dados', alguns excertos de textos produzidos durante essa reunião, destacando em itálico aspectos relevantes para a análise.

\section{Discussão dos dados}

Logo no início da Reunião, o professor regente (PR), que já tinha experiência de sala de aula naquela escola, relata um pouco de sua percepção sobre os alunos e como trabalha com eles:

(1) PR:[...]Eles (os alunos) têm um passo um pouco devagar, eu ando devagar pra eles poderem aprender, então eu acho que tem um propósito pedagógico aí sim, só que daí, por exemplo, nesse caso que tem um aluno do oitavo $\mathrm{D}$, aí você tem uma questão disciplinar um pouco maior.

Antes mesmo de realizar uma análise em nível micro, nota-se, na maneira que o professor regente identifica os alunos como lentos, fazendo com que o professor tenha que desacelerar, também, o processo de ensino, além de haver uma questão disciplinar, que nos próximos textos é apresentada, na verdade, como problemas de indisciplina que, juntamente com o passo lento dos alunos, dificulta o processo de ensino e de aprendizagem de língua inglesa. Neste excerto, podemos observar, na voz do professor: "Eles (os alunos) têm um passo um pouco devagar, eu ando devagar pra eles poderem aprender", uma declaração assertiva (modalidade epistêmica), que pode ser identificada pelo verbo "ter" no presente do indicativo, conjugado pela terceira pessoa do plural, representando o ritmo dos alunos, seguido do verbo "andar", conjugado pela primeira pessoa do singular, representando a ação do professor, que está também no presente do indicativo, mostrando um alto nível de comprometimento com o que se afirma, sem traços modais que distanciem o ator social de sua responsabilidade e comprometimento com o que é falado.

No segundo destaque, "você tem uma questão disciplinar um pouco maior", apesar de ser uma asserção, o professor não mais se posiciona em primeira pessoa do singular, mas, utiliza a segunda, provocando um distanciamento da identificação com quem tem um problema, por ele representado como "uma questão disciplinar um pouco maior". Fala que também pode representar uma avaliação indesejável, ao dizer que a questão é um pouco maior, na qual "maior" também pode ser interpretado como "mais complicada" e a indisciplina dos alunos como um problema de difícil solução. Apesar do alto nível de comprometimento com o que diz no primeiro destaque, a asserção atribui aos alunos a característica de ter "um passo um pouco devagar" e, por isso, o fato do professor andar "um pouco mais devagar para eles poderem aprender", a atribuição do adjetivo "devagar", utilizado para avaliar os alunos, carrega uma conotação negativa, fazendo com que o professor também tenha que trabalhar mais devagar do que o ritmo esperado para que a aprendizagem ocorra, o que, assim como a questão disciplinar um pouco maior, indica um aspecto indesejável para a prática docente.

Com relação as questões indesejáveis do contexto, como a indisciplina, discutimos algumas possíveis soluções em outros textos, dos quais trago alguns excertos com falas do professor regente $(\mathrm{PR})$, da professora formadora $(\mathrm{PF})$ e de uma professora em formação (PeF1): 
(2) PR: [...] aí você tem uma solução: dispensa o aluno, dá suspensão, dá, né, faz, tira todos os privilégios, etc.

(3) PF: [...] quando eu falo para a gente fazer algo, eu acho que é algo assim mesmo, positivo, não de excluir, não de não querer lidar com eles, né, com esses alunos, mas, ao contrário, de tratar disso abertamente com eles, com os pais, chamar os pais, por exemplo[...]

(4) PR: [...] chamar o aluno e dizer isso, dizer: "olha, você é bom, né, mas quando você tem esse comportamento, você não tá fazendo uma coisa ruim só pra você, você também tá fazendo pros seus colegas, que não conseguem prestar atenção" [...] e essa é uma coisa que preocupa muito.

(5) PeF1: [...] e essa questão de "ah, o pai participar mais da sala", ou sei lá, traz e olha: "pai, essa é a sala tal e a gente precisa conversar sobre o seu filho que se não eu vou dar suspensão mesmo"

As possíveis soluções discutidas nos excertos são: tomar medidas punitivas (2 e 5), trazer o aluno para participar da solução do problema (3 e 4) e convocar os pais ( 3 e 5). Tais soluções são representadas de diferentes formas. No excerto (2), por exemplo, pude observar características da modalidade deôntica em prescrições com os verbos "dispensa", "dá", e "tira", que, informalmente, estão no presente do indicativo, mas, que se reformulados de acordo com a norma culta, estariam no imperativo, como "dispense", "dê", e "tire", caracterizando as possíveis medidas punitivas como solução do problema indisciplina. $\mathrm{O}$ mesmo acontece no excerto (3), no qual a prescrição aparece nos verbos "fazer", "tratar" e "chamar" como prescrições desejáveis (avaliação), em contraste com as proscrições (modalidade deôntica) "não excluir" e "não querer lidar", que representam ações não desejáveis (avaliação) de serem realizadas por professores. Além disso, o adjetivo "positivo" e o advérbio de modo "abertamente" caracterizam avaliações positivas da professora formadora com relação às trazer alunos e pais para a solução do problema. Da mesma maneira que no excerto (3), o verbo "chamar" também aparece no excerto (4), seguido de "dizer" como prescrições desejáveis (modalidade deôntica e avaliação) e, além disso, com relação à avaliação, os adjetivos "bom" e "ruim" presentes no excerto (4) identificam ambos o aluno (bom) e seu comportamento (ruim), ou seja, ao mesmo tempo que o aluno pode ser avaliado positivamente como bom, ele pode ter um comportamento indisciplinado, que é avaliado como ruim tanto para ele, quanto para os outros alunos que "não conseguem prestar atenção", consequência negativa da indisciplina. Ainda no mesmo excerto (4), o verbo "preocupa", também carrega conotação negativa (avaliação), seguido do advérbio "muito", que intensifica a avaliação negativas do problema indisciplina. Outro aspecto que pode ser considerado como uma avaliação negativa é percebido no uso do verbo "dar" (suspensão), que aparece como uma prescrição no excerto (5). Como se trata de suspender o aluno, seguido do advérbio "mesmo", que exprime segurança, reforça-se a possibilidade de utilizar uma medida punitiva caso as soluções prescritas desejáveis representadas pelos verbos "participar", seguido do advérbio de intensidade "mais", "conversar" e "trazer" não funcionem. Por último, o emprego dos pronomes pessoais "eu" presentes nos excertos (2 e 5) e da locução pronominal "a gente" no excerto (2), indicam posicionamentos de alto nível de comprometimento dos falantes para com as prescrições que realiza, responsabilizando-se por elas em primeira pessoa do singular e, quando diz "a gente", responsabiliza os professores no geral, identificando-se como parte do grupo.

Além do aspecto linguístico em nível micro, possível pela análise usando as categorias de modalidade e avaliação, o processo de aprendizagem dos participantes durante as reuniões de ensino colaborativo se caracteriza pela mudança nos discursos, enquanto representações. No primeiro excerto, a voz do professor regente enfatiza a lentidão e introduz o problema indisciplina à discussão, identificando-se como um professor que precisa diminuir o ritmo do ensino para que haja aprendizagem dos alunos. A partir desse excerto, discutimos as possíveis soluções para o problema indisciplina. 
É partindo da discussão sobre indisciplina que as vozes do professor regente, da professora formadora e de uma professora em formação se revelam e conversam. Primeiramente, o professor regente apresenta medidas punitivas, como a análise linguística ilustrou. Em seguida, a professora formadora, em vez de concordar ou apropriar-se das representações de medidas punitivas, sugere que os professores discutam o problema com os alunos e pais de alunos, trazendo uma nova alternativa/maneira dos professores lidarem com o problema e dividindo a responsabilidade com alunos e pais. A partir da contribuição da professora formadora, o professor regente apropria-se das soluções propostas pela professora formadora em seu discurso, ou seja, apropria-se das representações feitas por ela, sugerindo, ao conversar com os alunos, que o professor apresente o problema indisciplina ao aluno indisciplinado, bem como o impacto negativo do problema no processo de aprendizagem de outros alunos e da preocupação que isso gera no professor regente quanto ao ensino. Por fim, uma professora em formação expõe sua voz, apropriando-se de discursos da professora formadora e do professor regente, trazendo como solução tanto chamar e conversar com pais de alunos, como, caso tal solução não funcione, retornar às medidas punitivas sugeridas pelo professor regente.

Estas mudanças no modo de se posicionar enquanto atores sociais mostra como o processo de ensino colaborativo, mais especificamente as reuniões, possibilitam discussões e mudanças de posicionamentos dos professores participantes, ainda que para este artigo eu tenha analisado apenas textos oriundos de uma reunião. Portanto, as avaliações negativas do contexto representadas por nós, professores participantes do trabalho colaborativo, tais como a identificação de alunos devagar e indisciplinados, ao serem compartilhadas, vão nos posicionando, a partir das nossa histórias, contextos, e lugares sociais, favoravelmente ao envolvimento do próprio aluno e da família na solução do problema indisciplina, bem como a tomada de medidas punitivas. Isso opera, ideologicamente, a favor da representação do professor como aquele responsável por solucionar os problemas presentes em sala de aula e ajudar os alunos e, ao mesmo tempo, naturaliza a escola como o lugar negado de aprendizagem, processo que é dificultado por problemas presentes no contexto, como o problema indisciplina.

\section{Conclusão}

Neste artigo, discorri sobre conceitos base, como os de perspectiva sócio-históricocultural, aprendizagem, ensino colaborativo, Análise de Discurso Crítica, noções de discurso, texto e categorias analíticas, bem como discuti alguns pressupostos teóricos e metodológicos que possibilitaram a análise de dados, seguido de um exercício de análise baseado nas categorias analíticas 'modalidade' e 'avaliação', propostas por Fairclough (2003a)

No entanto, um dos fatores que merecem atenção neste artigo ao que se refere ao ensino colaborativo, em particular às reflexões colaborativas que realizamos, como as que possibilitaram a produção dos textos presente nesse estudo, é como um professor em formação conecta-se com outro ao ocuparem posicionamentos e produzirem representações e identificações e como o discurso sofre mudanças oriundas de interações.

Neste estudo, o mesmo professor que começa a discussão expondo medidas punitivas para lidar com o problema 'indisciplina', ao discutir com os demais, acaba incorporando, em seu discurso, representações que englobam a divisão da responsabilidade de encontrar soluções para o problema. A representação inicial de solução que antes estava concentrada nas mãos somente do professor, estende-se para a comunidade escolar, como alunos e família.

As mudanças que evidenciam a aprendizagem, portanto, não se desvelam apenas em discutir sobre diferentes soluções para problemas que possam aparecer durante o processo de ensino. A aprendizagem também se deu em como os discursos foram articulados, 
reproduzidos ou modificados durante o processo de ensino colaborativo e práticas sociais proporcionadas por essa experiência colaborativa de ensinar língua inglesa em colaboração com diferentes professores, dotados de culturas e posicionamentos distintos, que se reuniram semanalmente para preparar-se para ensinar, encontrar soluções, dividir experiências, ideias e sugestões sobre e para a prática docente.

\section{Referências}

BRAY, J. N. et al. Collaborative inquiry in practice: Action, Reflection and Meaning Making. USA: Sage Publications, 2000. 180 p.

CAMPOS, Alcione Gonçalves. Fragmentos de identidades em (dis)curso. Dissertação (Mestrado em Estudos da Linguagem). Universidade Estadual de Londrina, Centro de Letras e Ciências Humanas, Programa de Pós-Graduação em Estudos da Linguagem, 2013. 123 p. COTS, Josep-Maria. Teaching 'with an attitude': Critical Discourse Analysis in EFL teaching. Elt Journal. 2006. P.336-345

EDWARDS, A. How can Vygotsky and his legacy help us understand and develop teacher education? Cultural-historical perspectives on teacher education and development. 2010. p. 63-75.

FAIRCLOUGH, Norman. Analyzing discourse: textual analysis for social research. New Fetter Lane, Londres: Routledge, 2003. 263 p.

FAIRCLOUGH, Norman. A dialectical-relational approach to critical discourse analysis in social research. Methods in Critical Discourse Analysis. 2 ed. Sage. 2009. p. 162-186. FAIRCLOUGH, Norman. Analysing discourse: textual analysis for social research. London; New York: Routledge. 2003a.

GUTIÉRREZ, K. Teaching and learning in the 21th Century. English Education, v. 32, n. 4. 2000. p. 290-298,

HALLIDAY, M.A.K.; MATTHIESSEN, Christian M.I.M. Introduction to functional grammar. 4 ed. Routledge, 2014. 790 p.

JASNIVSKI, C. C.; SILVA, A. A. P. Identidades em construção na voz de uma professora egressa de letras e suas expectativas de bases de conhecimento do professor. Semina:

Ciências Sociais e Humanas, Londrina, v. 32, n. 2. 2011. p. 127-142

JOHN-STEINER, V. Creative Collaboration. New York: Oxford University Press, 2000. $259 \mathrm{p}$.

JOHNSON, K. Second Language Teacher Education: a sociocultural perspective. Chapters 1 and 2. Defining a sociocultural perspective: Shifting epistemologies in Teacher Education. New York: Routledge, 2009. p. 1-16.

LEWIS, C.; KETTER, JEAN. Learning as social interaction: interdiscursivity in a teacher and researchers group. An Introduction to Critical Discourse Analysis in Education. New York: Routledge, 2004 [2011]. p. 128-153.

LEWIS, C., PYSCHER, T., \& STUTELBERG, E. Critical sociocultural perspectives in English education. Reclaiming English language arts methods courses: Critical Issues and Challenges for Teacher Educators in Top-Down Times. New York: Routledge. 2014 LIBÂNEO. A aprendizagem escolar e a formação de professores na perspectiva da psicologia histórico-cultural e da teoria da atividade. Educar. Curitiba. n. 24. Editora UFPR. 2004. p. 113-147.

MAGAlHÃes, I; MARTINS, A. R.; RESENDE, V. M. Análise de Discurso Crítica: um método de pesquisa qualitativa. Brasília: Editora da Universidade de Brasília. 2017. 260 p. MATEUS, E. Investigando oportunidades de aprendizagem em práticas situadas: Contribuições de Pesquisas Sóciocríticas para formação de professores de línguas. Em: MATEUS, Elaine; OLIVEIRA, Nilceia Bueno De. Estudos críticos da linguagem e 
formação de professores/as de línguas: Contribuições Teórico-Metodológicaas. Pontes Editores. 2014. 434 p.

MATEUS, E.; RESENDE, V. de M. (dis)posicionamentos em práticas sociais recontextualizadas: uma análise discursiva crítica do pibid. Em: VIEIRA, V. C.; RESENDE, V. de M. Práticas socioculturais e discurso: Debates transdisciplinares em novas reflexões. Livros LABCOM.2014. p. 75-94

MAZZEU, F. J. C. Uma proposta metodológica para formação continuada de professores na perspectiva histórico-social. Cadernos CEDES. 2009. 9 p.

MELO, Iran Ferreira de. Análise crítica do discurso: modelo de análise linguística e intervenção social. Estudos Linguísticos. v. 40. n. 3. 2011. Disponível em: <

https://revistas.gel.org.br/estudos-linguisticos/article/view/1257 >. Acesso em: 25 jan. 2018. PONTECORVO, C.; AJELLO, A.M.; ZUCCHERMAGLIO, C. Discutindo se aprende: interação social, conhecimento e escola. Porto Alegre: Artmed, 2005.

RAMALHO, V.; RESENDE, V. de M. Análise de discurso (para a) crítica: o texto como material de pesquisa: o texto como material de pesquisa. Pontes. 2011. 194 p.

ROTH, WOLFF-MICHAEL \& ROBIN, KENNETH \& ZIMMERMANN, ANDREA.

Coteaching/Cogenerative Dialoguing: Learning Environments Research as Classroom Praxis.

Learning Environments Research. 2002. 29 p.

Submetido em 14/10/2018

Aceito em 03/12/2018 